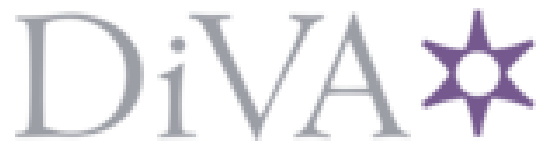

http://www.diva-portal.org

\title{
Postprint
}

This is the accepted version of a paper presented at LaTiCE 2017.

Citation for the original published paper:

Tshering, P., Lhamo, D., Yu, L., Berglund, A. (2017)

How do first year students learn C programming in Bhutan?.

In: Proc. 5th International Conference on Learning and Teaching in Computing and Engineering (pp. 25-29). IEEE Computer Society

https://doi.org/10.1109/LaTiCE.2017.12

N.B. When citing this work, cite the original published paper.

Permanent link to this version:

http://urn.kb.se/resolve?urn=urn:nbn:se:uu:diva-333933 


\section{How Do First Year Students Learn C Programming in Bhutan?}

\author{
Phurpa Tshering \\ Department of Information Technology \\ College of Science and Technology \\ Royal University of Bhutan \\ Phuentsholing, Bhutan \\ norvan012@gmail.com
}

$\mathrm{Lu} \mathrm{Yu}$

Department of Information Technology

Uppsala University

Uppsala, Sweden

School of Software Engineering

Tongji University

Shanghai, China

0628yulu0628@gmail.com

\author{
Dekar Lhamo \\ Department of Information Technology \\ College of Science and Technology \\ Royal University of Bhutan \\ Phuentsholing, Bhutan \\ dyenkalhamo@gmail.com
}

\author{
Anders Berglund \\ Uppsala Computing Education Research Group. UpCERG \\ Department of Information Technology \\ Uppsala University \\ Uppsala, Sweden \\ Anders.Berglund@it.uu.se
}

\begin{abstract}
This study explores how first year students in Information Technology Engineering at College of Science and Technology, Royal University of Bhutan, learn C programming. An online questionnaire was administrated to the students and asked about time spent in collaborative learning, individual coding and watching someone code. These data were analyzed in correlating to their exam scores. Students' ways of preparing for exam and their concept on $\mathrm{C}$ programming are categorized. Our result indicate a relationship between how the different ways of working relate to their exam results. Further, the insights of the project point to that learning of theory of programming and practicing programming go hand in hand in a $\mathrm{C}$ programming course. Our intent is that this study will be helpful for future teachers and students in programming courses in Bhutan and in its region.
\end{abstract}

Keywords-introductory programming, Bhutan, learning strategies, C programming, computing education research, higher education

\section{INTRODUCTION}

How do novice students learn programming when they first join university is a world-wide concern ([8], [10] and [13]). Kinnunen, Kontio and Pesonen [1] further claims that high dropout rate at CS courses during the first year are due to difficulties in learning the concepts of programming. In Bhutan, as a developing country, a majority of the beginner students in IT does not have any previous programming experience and in many cases no habits of accessing Internet. Considering this, getting to know how these beginner students adopt different learning approaches has captured our interest. The aim of this explorative study is to get insights on these students' learning practices and to get a starting point for future research on those that seem to lead to success in this context. To reach these aims, we decided to explore how the students go about learning to program, how their exams scores develop and further, to see if any relationship could be established between their approaches to study and their exams.

The paper is a development of group project in a master level course in Computing Education Research course offered at Uppsala University, Uppsala, Sweden. The $1^{\text {st }}$ and $2^{\text {nd }}$ authors were exchange students from College of Science and Technology, Royal University of Bhutan, and the $3^{\text {rd }}$ author was an exchange student at master level from Tongji University, China. The $4^{\text {th }}$ author was the teacher of the course and a researcher in the field at Uppsala University, Uppsala. After the completion of the course we jointly decided to write a paper based on the results with the hope to benefit learners of programming in Bhutan and elsewhere.

The rest of this paper is organized as follows: Section II explains the research question, while section III is describing the setting of the study. Section IV describes the methodologies used and also presents the ways to collect data. Section V shows our data analysis. Section VI discusses the result and Section VII concludes this study.

\section{RESEARCH QUESTION}

The goal of our study is to gain insights in how IT students in Bhutan go about learning $\mathrm{C}$ programming during their first semester, with the ultimate aims to benefit new students and in getting a basis for discussing how different learning strategies relate to learning. While our work is situated in a Bhutanese environment, we hope that the issues raised are relevant even in other cultures, particularly in societies with similar cultural 
and religious traditions. With this as a background, we focused on the following research questions:

1. How do students go about to learn $\mathrm{C}$ programming?

2. How do first year IT student learn basic concepts of C programming?

\section{THE SETTING OF THE STUDY}

This study has been carried out for first year IT students of College of Science and Technology (CST) at Royal University of Bhutan. This is the only technical college offering engineering degree in Information Technology in Bhutan. The programme is taught in English and has a yearly intake of approximately 40 students. The only course in their major during first semester is Introduction to C Programming, which includes 48 hours lab class (3 hours per week). Each lab consists of lab assignments, which are to be done during the lab sessions, as some students do not have personal laptops. There are three exams during the extent of the course. They take place after every one month of teaching. In this paper, the exams are labeled as exam1, exam 2 and the semester end exam. The marks obtained for first exam and second exam becomes a part of the continuous assessment. Both of these exams have full mark of 10 and pass mark of 4 . It is mandatory for all students to take these two exams to pass the course.

\section{METHODOLOGY AND DATA COLLECTION}

We sent web-based online questionnaire to the students in Bhutan, as the authors of this paper were in Uppsala during the time the study was made. We learned on literature, particularly [2] when constructing the questionnaire.

\section{A. Participants}

The participants were first year IT students of College of Science and Technology at RUB. The first two authors collected data through a questionnaire that was distributed towards the middle of the winter semester in 2016, three months into the academic year. At this time, the students had completed exam 1 and exam2. 21 students from the total of 35 $(60 \%)$ have responded. Out of the 21,8 (22\% of the students) were female.

\section{B. Data Collected \\ Scores of two exams}

We collected the exam scores of first two exams, exam1 and exam2.

\section{Data from closed questions}

We also collected data through closed ended questions that were multiple choices. Where first three questions $(\mathrm{Q} 2, \mathrm{Q} 3$, and Q4) discuss time spent in different ways of learning C programming and question 5 asks about exams. The questions and the possible answers were based on the experiences of the first two authors, who are students at CST.

The closed questions are as follows:

Q2. How much time do you think you spent learning programming together with one or more other students in groups during three hours lab session?

Q3. How much time do you think you have sat coding yourself having someone next to you during three hours lab session?

Q4. How much time do you think you have sat beside the computer, helping someone else coding during three hours lab session?

Q5. How do you think you prepare for C programming exam? You can choose more than one option?

\section{Data from open questions}

The third kind of questions were data based on open ended, and asked about students' understanding of $\mathrm{C}$ programming and the learning strategies that the students used during their first three months of the study in the course.

The open ended questions are:

Q6. How would you define C programming in your own words?

Q7. Can you please tell how you have studied during the course?

We used descriptive statistics to analyze closed questions since we wish to give a broad overview of how students learn programming. For the open questions, we did a categorization, inspired by phenomenography [15].

\section{DATA ANALYSIS}

\section{A. Exam scores and working time}

The Fig. 1 describes score distribution of the first two exams of the course. Fig. 1 indicates that the performance of most of the students had not changed very much between the two exams. However in exam1, the minimum score is very low and the average performance is comparatively lower than in exam2.It is worth noting that 12 students $(57 \%)$ had made improvement to exam2, with a few students (A8, A9, A15 and A16) had made huge improvement from exam1 to exam2.



Fig.1. Graph showing the scores of students in two exam and average scores. 




Fig.2. Showing individual students' time spent in group, coding alone and watching. X-axis shows name of student and their average scores.

Fig. 2 shows how much time the students indicated that they spent coding in groups, coding alone and watching someone coding. By comparing Fig. 1 students' scores with Fig. 2, we can see students A1, A2 and A3 are the ones who have performed high in both the exams. These three students had spent equal amounts of time in all activities: Group learning (31min-1h), coding themselves (0-30min) and watching and helping someone coding $(0-30 \mathrm{~min})$.

Students who had a low score (students A15 to A21) had spent approximately $1-2 \mathrm{~h}$ in group learning, and less than 2 hours in coding alone and watching and helping others code. Fig. 2 shows that students with greater average scores have spent only little time (0-30min) in watching someone coding, where students with average and low scores have spent considerably more time in watching someone coding. We also looked for the time spent by the students who have made huge improvement in their scores. Students A8 and A9 have spent same amount of time (1-2h) in group learning (Fig.2) and have spent less than 2 hour in coding alone and watching someone coding.

It is also seen that students A20, A21 who have performed low in both the exams are the ones who have spent maximum amount of time (2-3h) in group learning and even in coding alone and watching someone coding (Fig.2).

\section{B. Strategies to learn $C$ programming \\ Ways to prepare for exam}

The exam oriented educational system of Bhutan opened for asking how the students have prepared for their exams. For this purpose we asked "How do you think you prepare for $\mathrm{C}$ programming exam?" We analyzed the responses by dividing students into two groups, the "increase" category, being those that had improved between the two exams and the "decrease" group who had decreased their scores to exam2. Fig. 3 shows different ways of preparing for exams adopted by "increase" group. We see that all of them have studied for exam by reading theory and coding. None of them have studied by memorizing programs.

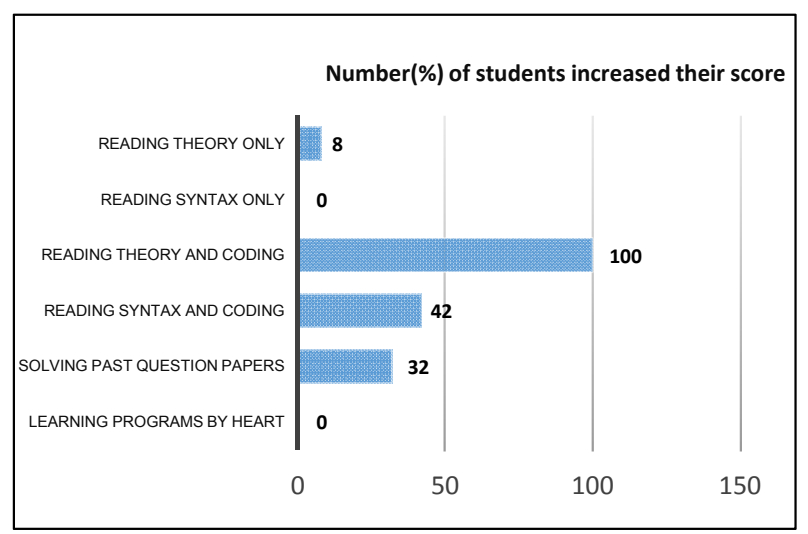

Fig.3. Showing different learning methods followed by the students who increased their scores between the two exams.

Most students in "decrease" group (Fig.4) have studied by reading syntax and doing coding. Some of them have also prepared for exam by memorizing the programs. 


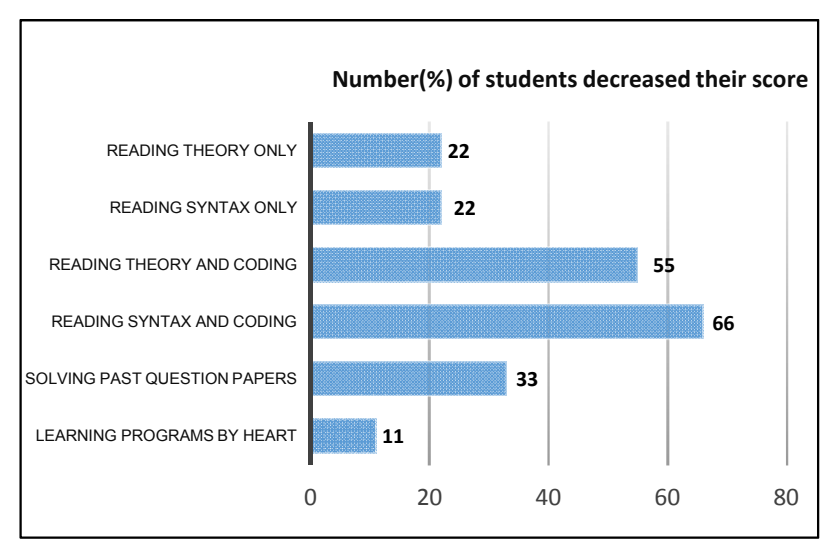

Fig.4. Showing different learning methods followed by the students who decreased their scores between the two exams.

\section{Ways of learning during the course}

We categorized quotes of how the students have gone about studying during $\mathrm{C}$ programming course into different categories showing different learning experiences.

Category I: Learning C programming from materials such as notes, slides given by teacher from lecture.

Learning materials such as lecture slides, sample programs are their basic way to learn $\mathrm{C}$ programming. The students who increased their scores between the two exams were just referring textbook [14] and few notes provided by tutor, which indicates that they don't write their own codes.

Student A7 tells us this in the following way

A7: I learn through browsing and through sir's demos on programming and theories that has been prepared by sir in ppt.

Category II: Understanding the theory and then practice by coding.

This category describes a way of studying where the students have understood theory before coding. After this being understood, they practice.

Let us read the answer of student A16 and A18:

A16: First getting the concept of the theory and applying practically.

A18: I have studied $\mathrm{C}$ programming by reading the basic theory and then doing some practical question.

Category III: Seeking help from friends or through Internet.

This category describes learning $\mathrm{C}$ programming by browsing internets and studying by seeking help from friends.

Student A9 and A12 supports this in following way:

A9: I first learn the theory and after understanding it I try to do coding and most of the time I browse through internet to learn more.

A12: I sturdy the slides that is provided by tutor and sometimes browsing internet and solving problems in computer.

Category IV: Learning $C$ programming by heart.

This category describes a learning of programming by learning difficult programs by heart.

Student A20 says:

A20: I memorized the codes which are difficult to understand.

\section{C. $\quad$ Students understanding of $C$ programming}

We categorized responses of question 6 , which asked the students to define $\mathrm{C}$ programming in their own words into following categories.

Category I: Defining C programming as a solution for solving problems.

This category defines $\mathrm{C}$ programming as a program written to solve real problems. Students in this category define $\mathrm{C}$ programming as a program to give solution for different problems.

Student A20 defines C programming in the following way:

A20: It is a program that we design using programming language to perform any kind of work faster easier and accurately and also safely.

Category II: Defining C programming as something that deals with computer language and code.

The second category expresses $\mathrm{C}$ programming as a part of computer language and defines $\mathrm{C}$ programming based on practical usage of programming in the classroom. It is defined as a set of instructions or codes that runs on computer software or simply just as a computer language, as expressed by student A4:

A4: $\mathrm{C}$ programming is a computer language.

Category III: Defining C programming as code to develop software.

Students had expressed $\mathrm{C}$ programming as a code to develop software or application out of it. They have not talked on content of $\mathrm{C}$ program rather had just thought of what can be produced out of it.

This category is supported by student A3:

A3: Computer programming used for developing software application.

\section{RESULT}

The analysis show that the students' performance do not change much from exam1 to exam2. The students with a high score have spent a considerable amount of time (1-2h) learning in groups rather than in coding alone or watching someone else coding. They have got high scores despite spending less time on the studies. We assume that this group of students might have a previous programming background.

The students who improved considerably to exam 2 have also spent more time in group learning (1-2h) than in coding alone and in watching others. Low performing students, who 
have low scores in both the exams have often spent much time in all three activities. We assume, this might be students with little or no programming experience or students who have studied programming by memorizing the programs, like for example A20.

In "increase" group all students had chosen reading theory and doing coding as one major way for preparing exams (Fig.3). No one had prepared the exam by reading syntax only and learning programs by heart.

In Fig.4, students in "decrease" group tend to have more than one choice of learning ways while preparing for exam. $66 \%$ of them is following "reading syntax and doing coding". Comparing Fig. 3 and Fig. 4, reading theory and syntax with the help of doing coding turn out to be the main method for both groups.

\section{DISCUSSION}

Little research is done on learning in higher education in Bhutan and its neighboring regions. Dahlin and Regni [5] point out that culturally situated studies increase the possibilities to explore the relationships between cultures and ways of learning. Our literature review gives at hand that this is one for the first, and possibly the only, publication on learning of computer science in Bhutan.

Our study gives glimpses in how Bhutanese beginner's students tackle their first programming course. Our aim has been to gain insights in how programming can be leant in certain developing countries. The ultimate aim is to offer advice to educational institutions, teachers and students on how enhance teaching and learning of programming.

As expected, students' learning of programming and their study strategies are, to a large extent, similar to what is known from Western students (for example [4], [6], [7] and [12]). For example, collaboration in different ways seem to enhance good learning. However, differences seem to appear, such as the roles of rote learning in Bhutan.

$\mathrm{C}$ programming is described by the Bhutanese students as a program solving real application problems and it is seen as code or program that can develop software applications. Other ways like analyzing programs before coding, learning from external resources and sometimes learning difficult programs by heart are some ways that the students have followed in the C programming course. It seems as if many of the Bhutanese students depend highly on the notes provided by course tutors.

Many of the students, who increased their scores between the first and the second exam, have to spend more time working in groups. This is consistent with result of McDowell, Bullock and Fernald [9] who show that students program better when they learn with others.

We hope and believe that these preliminary insights on how these first year Bhutanese students learn $\mathrm{C}$ programming correlated to their exam scores will help new IT freshmen's to make better choices of ways to learn to program. It also opens for exploring which ways of learning that are suitable for beginners Bhutanese students in learning programming.

\section{ACKNOWLEDGEMENT}

The authors wish to thank the students and staff at College of Science and Technology, Royal University of Bhutan, who made this study possible. The first three authors are further grateful to Royal University of Bhutan and Uppsala University, for their support to this project.

\section{REFERENCES}

[1] P. Kinnunen, M. M. Kontio and E. Pesonen, "Getting to know computer science freshmen," Koli Calling, Finland, vol. 13, pp. 59-66, November $14-172013$

[2] L. J. Höök and A. Eckerdal, "On the Bimodality in an Introductory Programming Course," International Conference on Learning and Teaching in Computing and Engineering, pp. 79-86, 2015.

[3] Lister, R., Clear, T., Simon, Bouvier, D., Carter, P., Eckerdal, A.,Jackova', J., Lopez, M., McCartney, R., Robbins, P., Seppälä, O.,Thompson, E. "Naturally occurring data as research instrument: analyzing examination responses to study the novice programmer". SIGCSE Bulletin, 41(4), pp. 156-173, 2010.

[4] A. Berglund and M. Wiggberg, "Students Learn CS in Different Ways," ITiCSE, vol. 06, pp. 265-269, 2006

[5] B. Dahlin and M. P. Pegmi, "Conceptions of learning among Nepalese students," Higher Education, vol. 33, pp. 471-493, 1997.

[6] A. Berglund and A. Eckerdal, "What do CS Students Try to Learn? Insights from a Distributed, Project-based Course in Computer Systems," Computer Science Education, vol. 16, no. 3, pp. 185-195, September 2006.

[7] Bruce, C., Buckingham, L., Hynd,J., McMahon, C., Roggenkmap, M, \& Stoodley, I. "Ways of Experiencing the Act of Learning to Program: a Phenomenographic Study of Introductory Programming Students at Univeristy," Information Technology Education, 3, pp. 143-160, 2004.

[8] M. McCracken, V. Almstrum, D. Diaz, M. Guzdial, D. Hagan, Y. B.-D. Kolikant, C. Laxer, L. Thomas, I. Utting and T. Wilusz, "A multinational, multi-institutional study of assessment of programming skills of first-year CS students," SIGCSE Bulletin, 33(4), pp. 125-140.

[9] C. McDowell, L. Werner, H. Bullock and J. Fernald, "The Effects of Pair-Programming on Performance in an Introductory Programming Course," ACM Technical Symposium on CSE, vol. 33, 2002.

[10] A. Robins, J. Rountree and N. Rountree, "Learning and Teaching Programming: A Review and Discussion," Computer Science Education, vol. 13, no. 2, pp. 137-172, 2003.

[11] L. Williams, E. Wiebe, K. Yang, M. Ferzli and C. Millar, "In Support of Pair Programming in the Introductory Computer Science Course," Computer Science Course, 2002.

[12] P. F. Campbell and G. P. McCabe, "Predicting the success of freshmen in a computer science major," Communications of the ACM, vol. 27, pp. 1108-1113, November 1984

[13] M. Corney, D. Teague and R. N. Thomas, "Engaging Students in Programming," Research and Practice in Information Technology, vol. 103, pp. 18-21, 2010.

[14] E. Balaguruswamy, Programming in ANSI C, Paschim Vihar, New Delhi: Tata McGraw Hill Education Private Limited, 2009.

[15] F. Marton and S. Booth, Learning and awareness, Mahwah, New Jersey, USA: Lawrence Erlbaum Associates, 1997. 